\title{
Polyesteramides with mixtures of poly(tetramethylene oxide) and 1,5-pentanediol
}

\author{
Li Guang \\ Department of Polymer Science, China Textile University, 1822 West Yan-an Road, \\ Shanghai 200051, P. R. China
}

and R. J. Gaymans*

Department of Chemical Technology, University of Twente, PO Box 217, 7500 AE

Enschede, The Netherlands

(Received 20 December 1996)

\begin{abstract}
Segmented polyesteramides have been synthesized from $\mathrm{N}, \mathrm{N}^{\prime}$-bis ( $p$-carbomethoxybenzoy)butanediamine as crystalline segments and mixtures of poly(tetramethylene oxide) (mol. wt. 1000) and 1,5-pentanediol as soft segments. The polymerization was carried out in the melt at $250^{\circ} \mathrm{C}$ for $1 \mathrm{~h}$ while vacuum was applied. The melting behaviour of the copolymers was studied by differential scanning calorimetry. The mechanical properties were investigated on injection moulded bars, using dynamic mechanical analysis. It was found that the copolymers with more than $50 \%$ molar ratio pentanediol showed two glass transition temperatures and two melting temperatures. The glass transition temperatures were not affected by the composition. The melting temperatures increased with pentanediol content. The pentanediol seems in part to be present as adjacent re-entry groups. The under-cooling for these copolymers was very small, which means that these segmented copolymers crystallize very fast. (C) 1997 Elsevier Science Ltd.
\end{abstract}

(Keywords: segmented copolymers; polyesteramides; poly(tetramethylene oxide); pentanediol)

\section{INTRODUCTION}

Alternating polyesteramides are regular copolymers and combine the good properties of polyester and polyamide, such as high melting temperature, fast crystallization, good mechanical properties, good solvent resistance and low water absorption ${ }^{1-1}$. They are interesting for applications of both engineering plastics and thermoplastic elastomers. Alternating polyesteramides which are of particular interest are those based on 1,4diaminebutane (Figure 1) 7-11. $^{7}$.

The esteramide unit with 1,4-diaminebutane terephthalate is named T4T. If the $R$ in this structure is a short chain alkyl the $T_{\mathrm{g}}$ is above room temperature (RT) and the material has engineering plastics properties ${ }^{9-11}$. If the $\mathrm{R}$ is a long chain alkyl or polyether the $T_{\mathrm{g}}$ is below RT and the material has thermoplastic elastomer behaviour ${ }^{7,8}$. In these thermoplastic elastomers with ether segments like polytetramethylene oxide (PTMO), the ether segments form the amorphous phase and give the system its low $T_{\mathrm{g}}$. The T4T-PTMO ${ }_{250-2900}$ segmented copolymers with a PTMO molecular weight ranging from 250 to 2900 have only one $T_{\mathrm{g}}$ and one $T_{\mathrm{m}}$. The shorter the PTMO segments, the higher the $T_{\mathrm{g}}$ of the system ${ }^{7,8}$. The increase in glass transition temperature can be explained as being due to the reduced mobility of a shorter chain between physical crosslinks. The

\footnotetext{
* To whom correspondence should be addressed
}

esteramide unit (T4T) has a uniform length and therefore crystallizes very fast. The melting temperature was found to increase with decreasing PTMO length. The increase in melting temperature was explained as being due to the lower amount of PTMO in the segmented copolymer which can act as a 'solvent' for the crystalline region ${ }^{7,8}$. The torsion modulus in the region between $T_{\mathrm{g}}$ and $T_{\mathrm{m}}$ was found to be very little dependent on temperature. This effect is typical for segmented copolymers with a uniform length of crystallizable segment ${ }^{12,13}$. This suggests that the physical crosslinks in these polymers are very stable, nearly as stable as chemical crosslinks.

Polyesteramides with 1,6-hexanediamine (T6T) and mixtures of PTMO ${ }_{1000}$ and 1,6-hexanediol (HDO) have also been studied ${ }^{3-6}$. In these copolymers PTMO $_{1000}$ with a molecular weight of 1000 is replaced in steps by HDO. The T6T was found to be immiscible with the PTMO phase, and in T6T-PTMO ${ }_{1000}$ the T6T was fully crystallized $^{6}$. T6T-(PTMO $\left.1000 / \mathrm{HDO}\right)$ copolymers have two melting temperatures. The lower $T_{\mathrm{m}}$ of T6T-PTMO ${ }_{1000}$ increases slightly with HDO content from $111^{\circ} \mathrm{C}$ to $119^{\circ} \mathrm{C}$. The higher $T_{\mathrm{m}}$ of T6T-HDO increases strongly

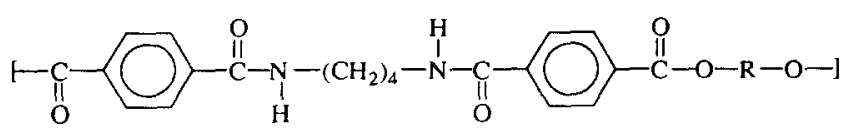

Figure 1 Polyesteramides based on T4T 


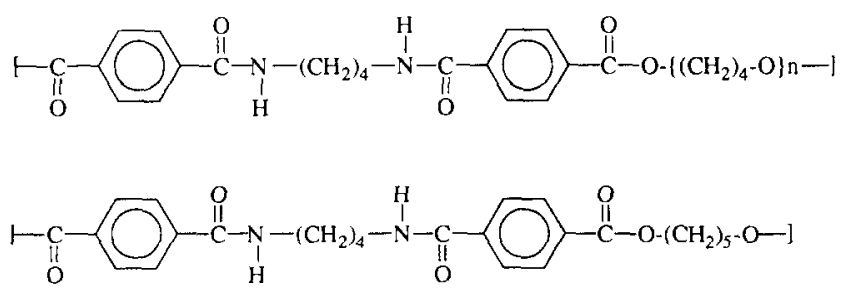

Figure $2 \mathrm{~T} 4 \mathrm{~T}-\left(\mathrm{PTMO} \mathrm{T}_{1000} / \mathrm{PDO}\right)$ copolymer

with HDO content ${ }^{4}$. The crystalline morphology of these copolymers is lamellar for T6T-HDO and changes with $\mathrm{PTMO}_{1000}$ to smectic-like lamellae and eventually to lamella-like micro paracrystals ${ }^{5,6}$. The lateral dimensions of the lamellae increase with increasing HDO content. T4T-PTMO $250-1000$ polymers have a lamellar morphology ${ }^{8}$.

Recently, Eisenbach et al..$^{13}$ showed that the properties of segmented copolymers can be further enhanced if adjacent re-entry groups can be built in. These copolymers had a larger width of the lamellar structures and a higher elongation at break. With adjacent re-entry groups the number of chains in the amorphous phase is reduced and results in less crowding in the amorphous phase and possibly also fewer chain entanglements. Short chain diols such as octanediol and hexanediol seem to be able to form adjacent re-entry groups ${ }^{14}$.

T4T polymers with short chain diols, such as pentanediol, have a high glass transition temperature $\left(100-120^{\circ} \mathrm{C}\right)$ and a high melting temperature $(240-$ $\left.280^{\circ} \mathrm{C}\right)^{9}$. These $\mathrm{T} 4 \mathrm{~T}$-diol polymers seem to have a lamellar structure with a thickness of about two T4T-diol units $^{15}$. So a part of the diol is in the crystalline phase. With PDO, although the diol is uneven, the T4T-diol polymer is fast crystallizing and highly crystalline ${ }^{9}$.

We studied T4T-PTMO ${ }_{1000} / \mathrm{T} 4 \mathrm{~T}-\mathrm{PDO}$ copolymers (Figure 2) by replacing PTMO stepwise with 1,5pentanediol (PDO) in the T4T-PTMO ${ }_{1000}$ segmented copolymers. The PDO might be either in the PTMO amorphous phase, the T4T crystalline phase or possibly in the interphase as an adjacent re-entry group.

\section{EXPERIMENTAL}

\section{Materials}

Dimethyl terephthalate (DMT), 1,4-butanediamine (BDA), anhydrous toluene, anhydrous methanol, $\mathrm{m}$ xylene, $n$-butanol and $\mathrm{N}$-methyl-2-pyrrolidone (NMP) were obtained from Merck, The Netherlands. Lithium was purchased from Aldrich. BDA and $n$-butanol were distilled prior to use. $\mathrm{LiOCH}_{3}$ was prepared by adding lithium to anhydrous methanol $(1.25 \mathrm{M})$. PTMO 1000 with a molecular weight of 1000 was kindly given by Bayer.

\section{Synthesis of $N, N^{\prime}$-bis(p-carbomethoxybenzoy)- butanediamine ${ }^{16}$}

DMT $(275 \mathrm{~g}, 1.42 \mathrm{~mol})$ was dissolved in $1100 \mathrm{ml}$ anhydrous toluene and $85 \mathrm{ml}$ anhydrous methanol at $60^{\circ} \mathrm{C}$ in a 2 litre flask, equipped with mechanical stirrer, condenser, calcium chloride tube and nitrogen inlet. After $10-20 \mathrm{ml}$ catalyst solution $\left(\mathrm{LiOCH}_{3}\right.$ in $1.25 \mathrm{M}$ methanol) was added, the temperature was raised to $65^{\circ} \mathrm{C}$. Then $34 \mathrm{ml} \mathrm{BDA}$ dissolved in $150 \mathrm{ml}$ toluene and $10 \mathrm{ml}$ methanol was added dropwise over 30-60 minutes. Once the BDA addition started, the nitrogen flow was stopped to avoid evaporation of BDA. After the addition of $\mathrm{BDA}$, the temperature was raised to $90^{\circ} \mathrm{C}$ in 150 minutes. The reaction was maintained for 240 minutes at $90^{\circ} \mathrm{C}$. The precipitated T4T-dimethyl was separated by hot filtration over a cellulose funnel. Subsequently the T4T-dimethyl was washed twice in hot $m$-xylene and filtered again, then dried in a vacuum oven at $80^{\circ} \mathrm{C}$ overnight. To purify the T4T-dimethyl, the product was recrystallized from hot $\mathrm{NMP}\left(50 \mathrm{gl}^{-1}\right.$ at $\left.160^{\circ} \mathrm{C}\right)$ and washed twice in hot acetone. The T4T-dimethyl was dried overnight in a vacuum oven at $80^{\circ} \mathrm{C}$. The purity was determined by H-n.m.r. ${ }^{16}$.

\section{Polymerization}

The reactions were carried out in a $250 \mathrm{ml}$ stainlesssteel vessel, immersed in an oil bath, with nitrogen inlet and mechanical stirrer. A typical example of copolymerization of $\mathrm{T} 4 \mathrm{~T}-\left(\mathrm{PTMO}_{1000} / \mathrm{PDO}\right)$ with a $\mathrm{PTMO}_{1000} /$ 1,5-pentanediol at molar ratio $80 / 20$ is given below. First, $18.56 \mathrm{~g}(0.045 \mathrm{~mol}) \mathrm{T} 4 \mathrm{~T}$-dimethyl, $36 \mathrm{~g}(0.036 \mathrm{~mol})$ PTMO $_{1000}, 0.112 \mathrm{~g}(0.0108 \mathrm{~mol}, 20 \%$ excess $) 1,5$-pentanediol were added to the vessel. Then the vessel was heated to $170^{\circ} \mathrm{C} ; 15 \mathrm{~min}$ later, $5 \mathrm{ml}$ catalyst solution was added. The reaction was kept at $170^{\circ} \mathrm{C}$ for $30 \mathrm{~min}$, then the temperature was raised to $250^{\circ} \mathrm{C}$ and vacuum was applied for $30 \mathrm{~min}$ at $10-15 \mathrm{mmHg}$, and subsequently for $60 \mathrm{~min}$ at about $1-2 \mathrm{mmHg}$. After this the reaction was stopped and the reactor was slowly cooled to room temperature, the vacuum being maintained during cooling. The obtained product was cryo-ground in a Fritsch Pulverisette and dried overnight in a vacuum oven at $80^{\circ} \mathrm{C}$.

N.m.r.

Proton n.m.r. and spectra were recorded on a Bruker AC 250 spectrometer at $250.1 \mathrm{MHz}$. Trifluoroacetic acid (TFA-d) was used as solvent without internal standard.

\section{Viscometry}

The inherent viscosity $\left(\eta_{\text {inh }}\right)$ of the polymers was measured using a $0.1 \mathrm{~g} \mathrm{dl}^{-1}$ solution in $\mathrm{PhOH} / \mathrm{C}_{2} \mathrm{Cl}_{4} \mathrm{H}_{2}$ $(50 / 50 \mathrm{~mol}$ ratio) and a capillary Ubbelohde $1 \mathrm{~B}$ viscometer, placed in a water bath at $25^{\circ} \mathrm{C}$.

\section{Differential scanning calorimetry (d.s.c.)}

D.s.c. spectra were recorded on a Perkin Elmer DSC7 apparatus with a PE-7700 computer and TAS-7 software; 3-9 $\mathrm{mg}$ dried samples were used. The samples were first heated to $300^{\circ} \mathrm{C}$, kept $2 \mathrm{~min}$ at that temperature, cooled to RT and heated up again to $300^{\circ} \mathrm{C}$. The heating and cooling rates were $20^{\circ} \mathrm{C} \mathrm{min}^{-1}$. The peak temperature was taken as the transition temperature and the area under the curve as the enthalpy $\Delta H$. Tin was used as a calibration standard.

\section{Injection moulding}

Samples for the torsion experiment were prepared on an Arburg- $\mathrm{H}$ manual injection moulding machine. The temperature set for melting the polymers was $230^{\circ} \mathrm{C}$, and the mould temperature was room temperature.

\section{Dynamic mechanical analysis (d.m.a.)}

A Myrenne ATM3 torsion pendulum instrument was used at a constant frequency of $1 \mathrm{~Hz}$. Samples of $50 \mathrm{~mm}$ length (clamp length), $7-8 \mathrm{~mm}$ width and $2 \mathrm{~mm}$ thickness were monitored at a heating rate $1.8^{\circ} \mathrm{Cmin}^{-1}$. The 
Table 1 Data for T4T-(PTMO $1000 / \mathrm{PDO})$ polymers

\begin{tabular}{|c|c|c|c|c|c|c|c|c|c|c|c|c|}
\hline PTMO/PDO & $\begin{array}{l}\text { Viscosity } \\
\left(\mathrm{dl} \mathrm{g}^{-1}\right)\end{array}$ & $\begin{array}{l}\text { Diol } \\
\text { (av. } M_{\mathrm{n}} \text { ) }\end{array}$ & $\begin{array}{l}\mathrm{T} 4 \mathrm{~T} \\
\text { (fraction) }\end{array}$ & $\begin{array}{l}T_{\mathrm{m}, \mathrm{A}} \\
\left({ }^{\circ} \mathrm{C}\right)\end{array}$ & $\begin{array}{l}T_{\mathrm{m}, \mathrm{B}} \\
\left({ }^{\circ} \mathrm{C}\right)\end{array}$ & $\begin{array}{l}T_{\mathrm{c}, \mathrm{A}} \\
\left({ }^{\circ} \mathrm{C}\right)\end{array}$ & $\begin{array}{l}T_{\mathrm{c}, \mathrm{B}} \\
\left({ }^{\circ} \mathrm{C}\right)\end{array}$ & $\begin{array}{l}\Delta H_{\mathrm{m}, \mathrm{A}} \\
\left(\mathrm{Jg}^{-1}\right)\end{array}$ & $\begin{array}{l}\Delta H_{\mathrm{m}, \mathrm{B}} \\
\left(\mathrm{Jg}^{-1}\right)\end{array}$ & $\begin{array}{l}T_{\mathrm{g}, \mathrm{A}} \\
\left({ }^{\circ} \mathrm{C}\right)\end{array}$ & $\begin{array}{l}T_{\mathrm{g}, \mathrm{B}} \\
\left({ }^{c} \mathrm{C}\right)\end{array}$ & $\begin{array}{l}G^{\prime}\left(25^{\circ} \mathrm{C}\right) \\
(\mathrm{MPa})\end{array}$ \\
\hline $100 / 0^{a}$ & 1.18 & 1000 & 0.292 & 153 & & 137 & & 27 & & -65 & & 65 \\
\hline $100 / 0$ & 0.98 & 1000 & 0.292 & 152 & & 135 & & 25 & & -67 & & 55 \\
\hline $95 / 5$ & 0.93 & 955 & 0.302 & 148 & & 141 & & 28 & & -67 & & 55 \\
\hline $90 / 10$ & 0.70 & 910 & 0.312 & 153 & & 144 & & 16 & & -67 & & 55 \\
\hline $80 / 20$ & 0.66 & 820 & 0.334 & 158 & & 146 & & 20 & & -67 & & 63 \\
\hline $60 / 40$ & 0.62 & 641 & 0.391 & 170 & 230 & 152 & 225 & 11 & 5.4 & -66 & & 89 \\
\hline $40 / 60$ & 0.54 & 462 & 0.471 & 175 & 242 & 159 & 247 & 7.4 & 18 & -68 & 120 & 193 \\
\hline $20 / 80$ & 0.34 & 283 & 0.593 & 182 & 258 & 154 & 236 & 5.9 & 27 & -67 & 120 & 365 \\
\hline $0 / 100$ & 0.33 & 104 & 0.798 & & 274 & & 260 & & 41 & & 120 & \\
\hline $0 / 100^{b}$ & 1.05 & 104 & 0.798 & & 276 & & 262 & & 40 & & 121 & 1087 \\
\hline
\end{tabular}

${ }^{a}$ Data from Gaymans et al.

${ }^{b}$ Data from Serrano et al. ${ }^{9}$

storage moduli $G^{\prime}$ and loss moduli $G^{\prime \prime}$ of the samples were obtained during the set temperature range. The maximum of the loss moduli was taken as the glass transition temperature $T_{\mathrm{g}}$.

\section{RESULTS AND DISCUSSION}

Synthesis of $T 4 T-\left(P T M O_{1000} / P D O\right)$ polymers

The polymers $\mathrm{T} 4 \mathrm{~T}-\left(\mathrm{PTMO} \mathrm{T}_{1000} / \mathrm{PDO}\right)$ were synthesized from T4T-dimethyl and a mixture of PTMO $\mathrm{PM}_{100}$ and PDO. The average molecular weight of $\mathrm{PTMO}_{1000}$ is 1000 .

The T4T-dimethyl used was produced according to the method reported in the literature ${ }^{16}$. The T4Tdimethyl melting temperature was $263-266^{\circ} \mathrm{C}$, the heat of fusion $\Delta H_{\mathrm{m}}$ was $160-165 \mathrm{Jg}^{-1}$, and the purity according to H-n.m.r. was $96-98 \%$.

The polymerization of T4T-dimethyl with PTMO $_{1000}$ and PDO was carried out in the melt. A certain excess of PDO was employed, especially for high PDO content polymers. The PDO acts in this stage too as solvent for T4T-dimethyl and liquefies the reaction mass. At the end of the reaction the excess PDO was stripped off. The polymers obtained were almost white. The viscosity and other data of the polymers are given in Table $I$. The inherent viscosities were less than 1; this means that the molecular weights of the polymers are not very high.

${ }^{1}$ H n.m.r. data were recorded to study the composition of the copolymers. The chemical shifts observed on these materials are given in Table 2.

Table 2 Chemical shift of ${ }^{1} \mathrm{H}$ n.m.r. in $4 \mathrm{NT}\left(\mathrm{PTMO}_{100} / \mathrm{PDO}\right)$

\begin{tabular}{lll}
\hline Segment & Proton & $\begin{array}{l}\text { Chemical shift } d \\
(\mathrm{ppm})\end{array}$ \\
\hline T4T & $\begin{array}{l}\text { aromatic protons: } \\
\text { amide side }\end{array}$ & \\
& ester side & $8.12-8.15$ \\
& $\mathrm{C}(\mathrm{O})-\mathrm{N}(\mathrm{H})-$ & $8.43-8.46$ \\
& $\mathrm{CH}_{2}$ & 4.05 \\
& $\mathrm{CH}_{2}-\mathrm{CH}_{2}$ & 4.11 \\
pentadiol & $\mathrm{C}(\mathrm{O})-\mathrm{O}-\mathrm{CH}_{2}$ & 2.16 \\
\multirow{2}{*}{ PTMO } & $\mathrm{CH}-\mathrm{CH}$ & 4.76 \\
& $\mathrm{C}(\mathrm{O})-\mathrm{O}-\mathrm{CH}_{2}$ & 2.16 \\
& $\mathrm{CH}-\mathrm{O}-\mathrm{CH}_{2}$ & 5.08 \\
& $\mathrm{CH}_{2}-\mathrm{CH}_{2}$ & 4.64 \\
\hline
\end{tabular}

\section{Dynamic mechanical analysis}

Dynamic mechanical analysis (d.m.a.) was carried out on injection moulded bars. In Figures 3 and 4 the changes in storage and loss moduli with temperature are given. The PTMO P000 $_{1} / \mathrm{PDO}(100 / 0)$ and $(0 / 100)$ both show one $T_{\mathrm{g}}$ and one $T_{\mathrm{m}}$. T4T-PTMO ${ }_{1000}(100 / 0)$ has a sharp $T_{\mathrm{g}, \mathrm{A}}$

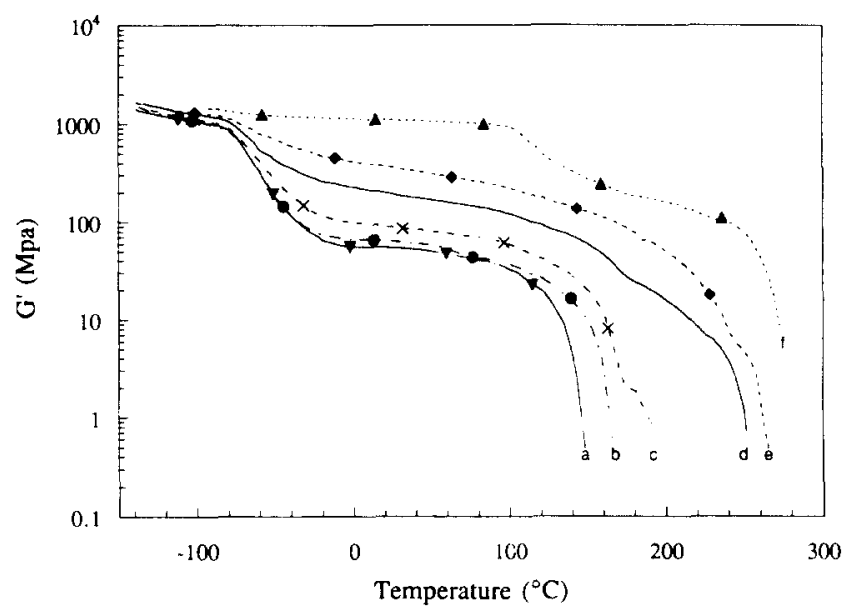

Figure 3 Storage modulus vs temperature of T4T- $\left(\mathrm{PTMO}_{1000} / \mathrm{PDO}\right)$ for different PTMO $1000 /$ PDO molar ratios: (a) $100 / 0$; (b) $80 / 20$; (c) $60 /$ $40 ;$ (d) $40 / 60 ;$ (e) $20 / 80 ;$ (f) $0 / 100$

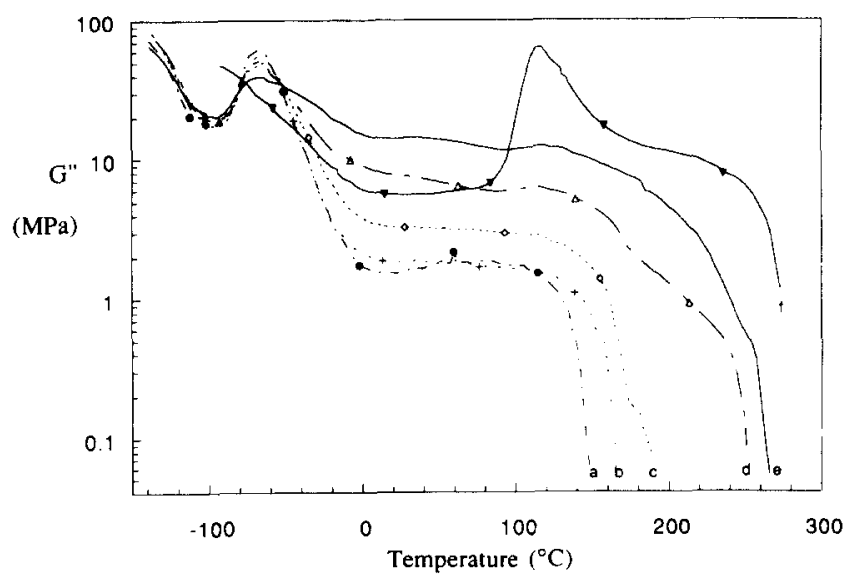

Figure 4 Loss modulus vs temperature of T4T-(PTMO $\left.{ }_{1000} / \mathrm{PDO}\right)$ for different PTMO $_{1000} / \mathrm{PDO}$ molar ratios: (a) 100/0; (b) 80/20; (c) 60/40; (d) $40 / 60 ;$ (e) $20 / 80 ;$ (f) $0 / 100$ 


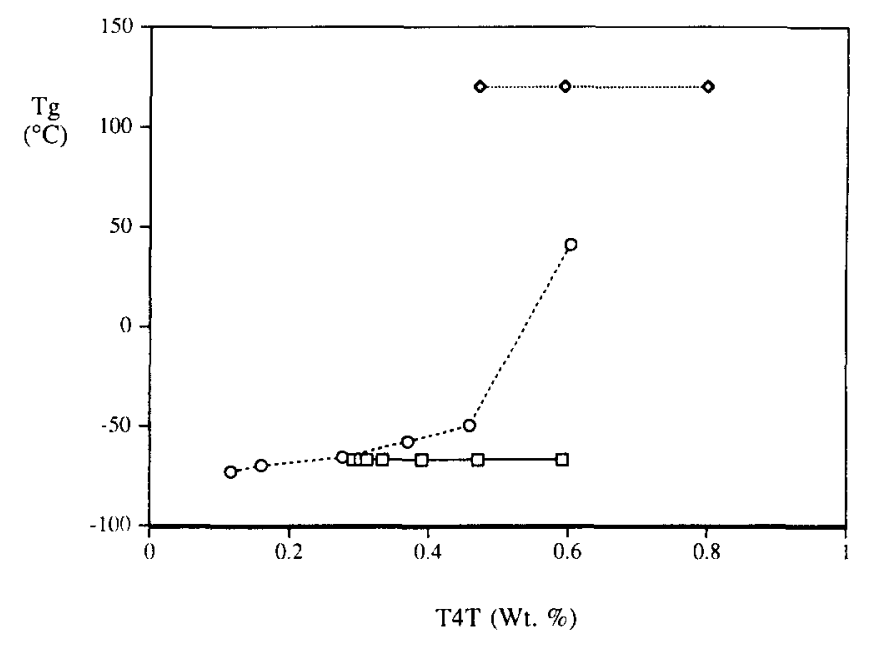

Figure 5 Glass transition temperature of T4T-(PTMO $1000 / \mathrm{PDO})$ and T4T-PTMO ${ }_{250-2900}$ as function of weight fraction T4T: $\square, T_{\mathrm{g} . \mathrm{A}} ; \diamond$, $T_{\mathrm{g}, \mathrm{B}} ; \mathrm{O}, \mathrm{T} 4 \mathrm{~T}-\mathrm{PTMO}_{250 \cdot 2900^{7}}$

at $-67^{\circ} \mathrm{C}$, a sharp $T_{\mathrm{m} \text { A }}$ at $153^{\circ} \mathrm{C}$ and a low modulus at room temperature. T4T-PTMO $\mathrm{PO}_{100}$ thus has typical thermoplastic elastomer properties. T4T-PDO $(0 / 100)$ has a $T_{\mathrm{g}, \mathrm{B}}$ at $120^{\circ} \mathrm{C}$ and a $T_{\mathrm{m}, \mathrm{B}}$ at $274^{\circ} \mathrm{C}$. This semicrystalline material has typical engineering plastics properties. The copolymers (40/60) and (20/80) show two $T_{\mathrm{g}} \mathrm{s}$ and two $T_{\mathrm{m}} \mathrm{s}$. The glass transition temperatures $T_{\mathrm{g}, \mathrm{A}}$ and $T_{\mathrm{g}, \mathrm{B}}$ are at $-67^{\circ} \mathrm{C}$ and $120^{\circ} \mathrm{C}$ respectively and do not shift with composition (Figure 5 ). This is different from T4T-PTMO $250-2900$, where there is one $T_{\mathrm{g}}$ which increases with decreasing PTMO length ${ }^{7}$.

The two $T_{\mathrm{g}} \mathrm{s}$ in $\mathrm{T} 4 \mathrm{~T}-\left(\mathrm{PTMO} \mathrm{O}_{1000} / \mathrm{PDO}\right)$ copolymers $40 / 60$ and $20 / 80$ mean that two fully phase-separated amorphous phases are present, the structure of which does not change with composition. The $T_{\mathrm{g}, \mathrm{A}}$ at $-67^{\circ} \mathrm{C}$ is due to a PTMO amorphous phase with no or little T4T present. The $T_{\mathrm{g}, \mathrm{B}}$ at $120^{\circ} \mathrm{C}$ is of a PDO-T4T amorphous phase; here T4T units are expected to be present. The $T_{\mathrm{g}} \mathrm{s}$ for the $60 / 40$ and 80/20 copolymers are only just visible in the $G^{\prime \prime}$-temperature plot. As they do not shift with PDO content, it is evident that in the $\mathrm{PTMO}_{1000}$ amorphous phase no or very little PDO is present and at the same time very little $\mathrm{PTMO}_{1000}$ is present in the T4T-PDO amorphous phase. In the comparable segmented copolymers PBT-PTMO 1000 the $T_{\mathrm{g}}$ of the PTMO phase changes with PBT content ${ }^{17}$. Some PBT is present here in the PTMO phase.

In the loss modulus $G^{\prime \prime}$ diagram of the T4T$\left(\mathrm{PTMO}_{1000} / \mathrm{PDO}\right)$ copolymers two melting temperatures can be observed (Figure 4). Thus two crystalline T4T phases seem to be present, a $T_{\mathrm{m}, \mathrm{A}}$ of T4T-PTMO and $T_{\mathrm{m}, \mathrm{B}}$ of T4T-PDO. $T_{\mathrm{m}, \mathrm{A}}$ and $T_{\mathrm{m}, \mathrm{B}}$ both increase with PDO content. This increase might be due to the decreasing volume fractions of amorphous material ${ }^{8} . T_{\mathrm{m}, \mathrm{B}}$ might also increase if the lamellar thickness increases further.

The storage modulus $G^{\prime}$ increases with PDO content over the whole temperature range (Figure 3). The level of $G^{\prime}$ is a function of the inherent modulus of the amorphous phase and the volume fraction crystalline phase. The dependence of storage moduli at room temperature on the weight fraction of T4T segments is given in Table 1 and Figure 6. The $\log$ of $G^{\prime}$ increases almost linearly with T4T content. The moduli are somewhat lower for $\mathrm{T} 4 \mathrm{~T}-\left(\mathrm{PTMO}_{1000} / \mathrm{PDO}\right)$ than for

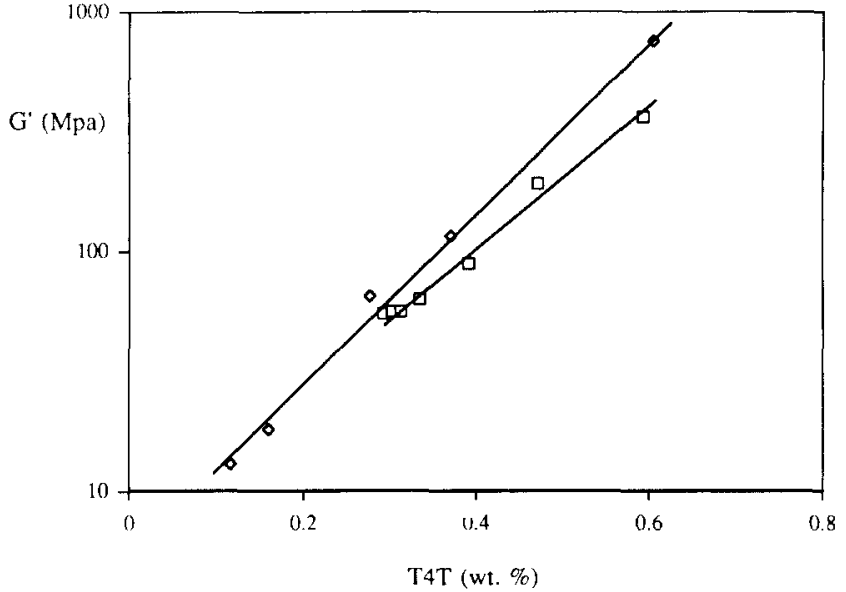

Figure 6 Storage modulus at $25^{\circ} \mathrm{C}$ vs weight fraction of T4T: $\square$, T4T $\left(\mathrm{PTMO}_{1000} / \mathrm{PDO}\right) ;$ ○, T4T-PTMO $250-2900^{7}$

T4T-PTMO $250-2900^{7}$. The lower moduli are difficult to explain.

The temperature dependence of modulus in the region of $T_{\mathrm{g}}-T_{\mathrm{m}}$ is very low for both T4T-PTMO 1000 and T4T-PDO. For the $\mathrm{PTMO}_{1000} / \mathrm{PDO}$ copolymers the decrease is somewhat stronger but still low.

\section{Differential scanning calorimetry}

The melting thermograms of the copolymers as obtained with d.s.c. are presented in Figure 7 and the data given in Table 1. T4T-PTMO ${ }_{1000}$ has a melting temperature $\left(T_{\mathrm{m}, \mathrm{A}}\right)$ of $152^{\circ} \mathrm{C}$ and $\mathrm{T} 4 \mathrm{~T}-\mathrm{PDO}$ has a melting temperature $\left(T_{\mathrm{m}, \mathrm{B}}\right)$ of $276^{\circ} \mathrm{C}$. The T4T$\left(\mathrm{PTMO}_{1000} / \mathrm{PDO}\right)$ copolymers have two melting temperatures (Figures 7 and 8). This is particularly clear for the $40 / 60$ and $20 / 80$ copolymers. Two melting temperatures of the T4T-(PTMO $\left.{ }_{1000} / \mathrm{PDO}\right)$ copolymers were also observed with d.m.a. This means that two crystalline phases are present. In these T4T polymers the T4T is the crystallizing unit and this unit is identical for T4T-PTMO and T4T-PDO. Despite this great similarity, surprisingly two crystalline phases have formed. The only possible difference we can see is that in T4T-PTMO the lamellae are built up with only one T4T unit ${ }^{8}$, while with T4T-PDO more than one T4T unit can be present

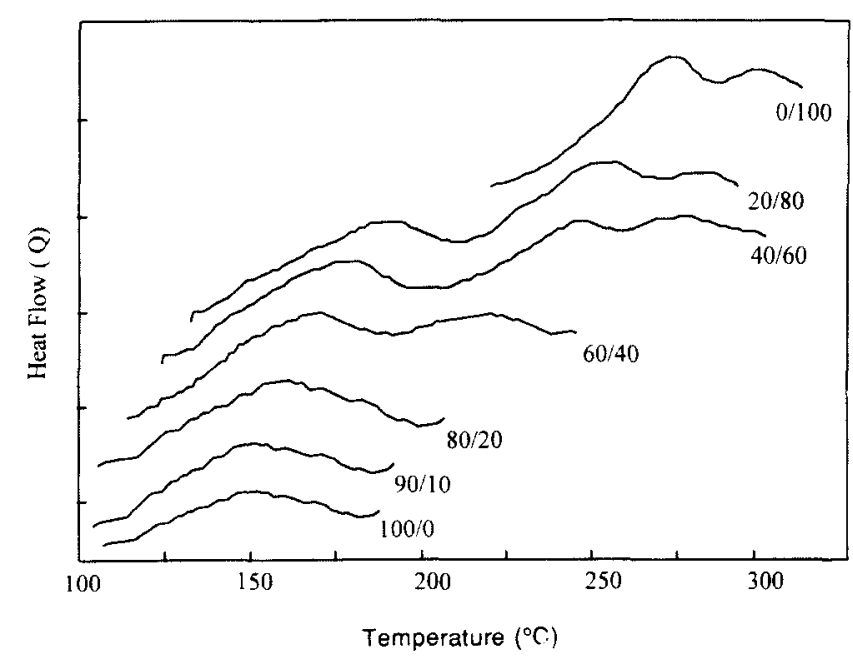

Figure 7 D.s.c. thermograms of $\mathrm{T} 4 \mathrm{~T}-\left(\mathrm{PTMO}_{1000} / \mathrm{PDO}\right)$ polymers 


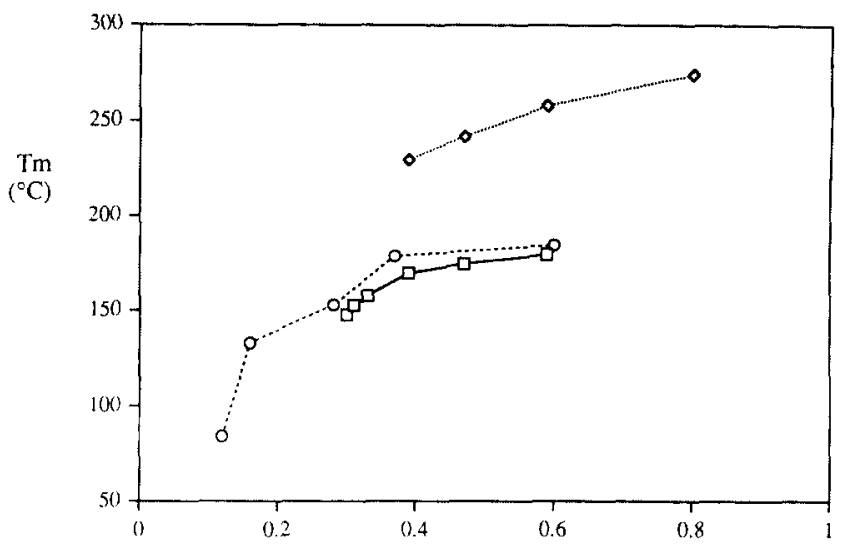

Figure 8 Melting temperatures of T4T-(PTMO $\left.{ }_{1000} / \mathrm{PDO}\right)$ and T4T$\mathrm{PTMO}_{250-2900}$ as function of weight fraction of T4T: $\square, T_{\mathrm{m}, \mathrm{A}} ; \diamond, T_{\mathrm{m}, \mathrm{B}}$; O, T4T-PTMO $2502900^{7}$

in a lamella ${ }^{15}$. This difference in lamellar structure must, we think, be the reason for the phase separation.

The change in the melting temperatures with T4T weight fraction is given in Figure 8. The lower melting temperature $\left(T_{\mathrm{m}, \mathrm{A}}\right)$ of $\mathrm{T} 4 \mathrm{~T}-\left(\mathrm{PTMO}_{1000} / \mathrm{PDO}\right)$ polymers shows almost the same dependence on the weight fraction of T4T as the T4T--PTMO $250-2900$ polymers ${ }^{7}$. In the T6T-(PTMO $1000 / \mathrm{HDO})$ copolymers the lower melting temperature was found to be nearly independent of HDO content ${ }^{4}$. The presence of PDO in the T4T$\left(\mathrm{PTMO}_{1000} / \mathrm{PDO}\right)$ copolymers increases this $T_{\mathrm{m}, \mathrm{A}} . \mathrm{PDO}$ is thus in some way influencing the $T_{\mathrm{m}, \mathrm{A}}$ although it is not present in the PTMO amorphous phase. Nor is PDO expected to be present in the T4T-PTMO 1000 crystalline phase because then a thickening of the lamella is taking place and with that a very strong temperature increase. The most logical suggestion seems to be that some PDO is present in the interphase and probably as an adjacent re-entry group. Diols are known to be able to form adjacent re-entry groups ${ }^{13,14}$. If some PDO is present as an adjacent re-entry group, the amount of PTMO per lamella is reduced and thus also the 'solvent' effect of $\mathrm{PTMO}_{1000}$. In this way the $T_{\mathrm{m}, \mathrm{A}}$ increase can be explained.

The $T_{\mathrm{m}, \mathrm{B}}$ was found to have a double melting endotherm like that observed for many semi-crystalline polymers ${ }^{18-20}$ and also polyesteramides ${ }^{9}$. The $T_{\mathrm{m}, \mathrm{B}}$ melting temperature increases too with $\mathrm{T} 4 \mathrm{~T}$ weight fraction. In the T6T$\left(\mathrm{PTMO}_{1000} / \mathrm{HDO}\right)$ copolymers the higher melting temperature increases with HDO content ${ }^{4}$. In T4T-PDO the PDO is taking part in the crystallization, leading to thicker lamellae 9 . The amount of lamellar thickening, and also $T_{\mathrm{m}, \mathrm{B}}$, probably depend on the concentration of the PDO.

The crystallization temperatures $T_{\mathrm{c}, \mathrm{A}}$ and $T_{\mathrm{c}, \mathrm{B}}$ match the melting temperatures $T_{\mathrm{m}, \mathrm{A}}$ and $T_{\mathrm{m}, \mathrm{B}}($ Table 1$)$. What is surprising is that the undercooling $\left(T_{\mathrm{m}, \mathrm{A}}-T_{\mathrm{c}, \mathrm{A}}\right)$ and $\left(T_{\mathrm{m}, \mathrm{B}}-T_{\mathrm{c}, \mathrm{B}}\right)$ are less than $20^{\circ} \mathrm{C}$, which is very small. These data are in line with those for T4T-PTMO ${ }_{250-2900}^{7,8}$ and T4T-diol ${ }^{9,10}$ polymers. This means an extremely fast crystallization of these copolymers. Probably in the melt the uniform T4T segments are already coupled through $\mathrm{H}$-bonding and, on cooling, they do not have to diffuse but only to pack better ${ }^{7-10}$. With increasing PDO content $\Delta H_{\mathrm{m}, \mathrm{A}}$ decreases, $\Delta H_{\mathrm{m}, \mathrm{B}}$ increases and the total crystallinity decreases. However, the $G^{\prime}$ above the $T_{\mathrm{g}}$

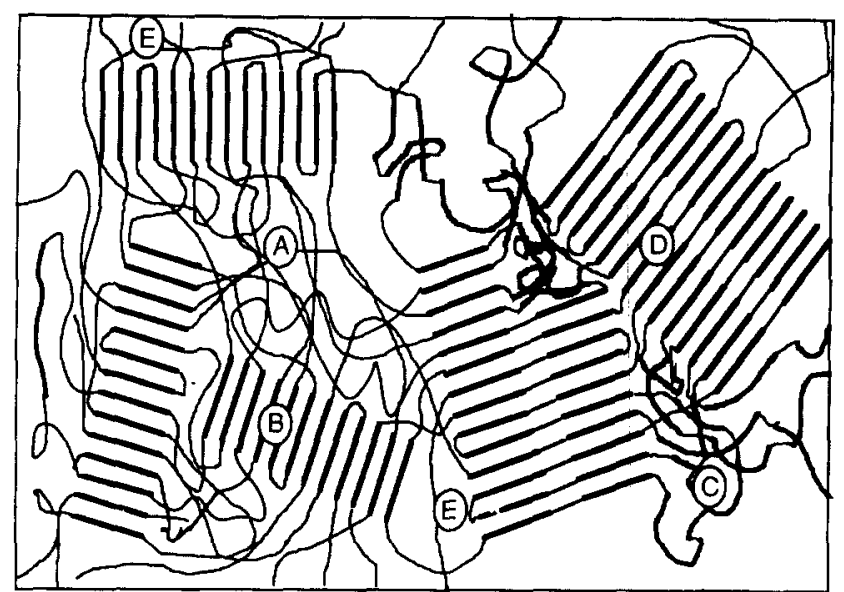

Figure 9 Model of morphology of T4T-(PTMO/PDO) polymers

increases with PDO content, which indicates a gradual increase in crystallinity.

\section{Structure}

The T4T- $\left(\mathrm{PTMO}_{1000} / \mathrm{PDO}\right)$ copolymers have two glass transition temperatures and two melting temperatures. The positions of the two glass transition temperatures are independent of composition and thus two fully phase-separate amorphous phases are present. Surprisingly, the melting temperatures change with composition. The amount of PDO has an effect on both $T_{\mathrm{m}, \mathrm{A}}$ and $T_{\mathrm{m}, \mathrm{B}}$. The effect of PDO can thus only be on the lamellar structures. The possible phases are drawn in a twodimensional cartoon (Figure 9), in which: $\mathrm{A}$ is the $\mathrm{PTMO}_{1000}$ amorphous phase with $T_{\mathrm{g}, \mathrm{A}}$, which does not contain T4T or PDO; $B$ is the uniform T4T crystallites, which are very thin and do not contain $\mathrm{PTMO}_{1000}$ or PDO; $\mathrm{C}$ is the T4T-PDO amorphous phase, which does not contain $\mathrm{PTMO}_{1000}$; D is the T4T-PDO crystalline phase, with thickness depending on the amount of PDO which takes part in the crystallization, and does not contain $\mathrm{PTMO}_{1000}$; and E is the PDO adjacent re-entry group which can be present both with the T4T and with the T4T-PDO lamellae.

PDO can thus be present in three ways: in the T4TPDO amorphous phase (C), in the crystalline T4T-PDO phase (D) and in the interphase as an adjacent re-entry group (E).

\section{CONCLUSION}

Copolymers of T4T-PTMO ${ }_{1000}$ and T4T-PDO have two amorphous and two crystalline phases and the amorphous phases are fully phase separated. This is surprising as PTMO and PDO are quite alike. The two crystalline phases seem to be due to crystallites of different lamellar thicknesses. Some PDO is possibly present in the interphase as an adjacent re-entry group. Although this is a complex copolymer system the undercoolings are very low, suggesting very high crystallization rates.

\section{REFERENCES}

1. Williams, J. L. R., Laakso, T. M. and Contois, L. E., J. Polym. Sci., 1962, 61, 353 . 
2. Borri, C., Sorta, E. and Zotteri, L., Polymer, 1975, 16, 565.

3. Cernia, E. and D'llario, L., J. Polym. Sci., Polym. Phys. Edn, $1985,23,4$.

4. Sorta, E. and della Fortuna, G., Polymer, 1980, 21, 728

5. Perego, G., Cesart, M. and della Fortuna, G., J. Appl. Polym. Sci., 1984, 29, 1141.

6. Perego, G., Cesart, M. and Vitali, R., J. Appl. Polym. Sci., 1984, 29, 1157.

7. Gaymans, R. J. and de Haan, J. L., Polymer, 1993, 34, 4360.

8. van Hutten, P. F., Mangnus, R. M. and Gaymans, R. J., Polymer, 1993, 34, 4193.

9. Serrano, P. J., Thuss, E. and Gaymans R. J., Polymer, (in press).

10. Serrano, P. J., van de Werff, B. A. and Gaymans R. J., Polymer, (in press).

11. Serrano, P. J. M., Gaymans, R. J. and Aerts, L., Polymer, (submitted).

12. Miller, J. A., Lin, S. B., Hwang, K. K. S., Wu, K. S., Gibson, P. E. and Cooper, S. L., Macromolecules, 1985, 18, 32.
13. Eisenbach, C. D., Baumgartner, M. and Gunter, C., Advances in Elastomers and Rubber Elasticity, ed. J. Las and J. E. Mark, Plenum, New York, 1987, p. 51.

14. Eisenbach, C. D., Hayen, H., and Nefzger, H., Makromol. Chem., Rapid Commun., 1989, 10, 463.

15. Serrano, P. J., van Duynhoven, P. J. M. and Gaymans, R. J., (to be published).

16. Serrano, P. J., van Bennekom, A. C. M. and Gaymans, R. J., Polymer, (submitted).

17. Boussias, C. M., Peters, R. H. and Still, R. H., J. Appl. Polym. Sci., 1980, 25, 855 .

18. Bassett, D. C., in Comprehensive Polymer Science, ed. G. Allen and J. C. Bevington, Pergamon, Oxford, 1988, vol. 1, chap. 35 , p. 880.

19. Nichols, M. E. and Robertson, R. E., J. Polym. Sci., Part B, Polym. Phys., 1992, 30, 305.

20. Woo, E. M. and Ko T. Y., Coll. Polym. Sci., 1996, 274, 309 . 